\title{
Seroprevalence of Hepatitis- A virus in North Karnataka and its changes over a 5 year period
}

\author{
Mahesh Kumar Shankar ${ }^{1}$, Sharon V. A.,** \\ ${ }^{\mathbf{1}}$ Assistant Professor, ${ }^{2} \mathrm{PG}$ Student, Dept. of Microbiology, Karnataka Institute of Medical Sciences, Karnataka, India
}

*Corresponding Author:

Email: drsharonva@gmail.com

\begin{abstract}
Introduction: Worldwide, the most common type of acute viral hepatitis is hepatitis A, transmitted via the fecal-oral route occasionally leading to death due to acute fulminant hepatitis. The present study was undertaken to study the seroprevalence of HAV infection in a tertiary care hospital over a five year period.

Materials and Methods: A cross-sectional study was conducted from January 2012 to December 2016 on samples of blood obtained from cases of clinically suspected hepatitis infection by IgM 'capture' assay ELISA.

Results: A total of 173 cases were included in the study. The number of positive cases were $35(20.2 \%)$. The percentage positivity rate of anti HAV IgM was higher among the children tested 32(30.8\%) when compared to adults tested $3(4.3 \%)$. Seasonal distribution showed maximum number of seropositive cases in the monsoon months.

Conclusion: Increase in the number of samples received during 2014 and 2015 and a zero positive rate in 2015 indicates a rise in the awareness about preventive measures against hepatitis A virus infection. Uniform and well structured protocols which monitor HAV cases and assess disease load are necessary to capture and probe into the sudden rise in the seropositivity, as seen in the last four months of 2016 in this study.
\end{abstract}

Keywords: Fulminant hepatitis, Feco-oral route, Hepatitis A, Sero prevalence.

\section{Introduction}

In India and other developing nations where sanitary conditions are inadequate acute viral hepatitis (AVH) is a public health problem of major concern. ${ }^{1}$

The most common form of acute viral hepatitis is hepatitis A, in the world. Endemicity of hepatitis A in various geographical regions is closely related to hygiene and socioeconomic development indicator levels. ${ }^{2}$

The Hepatitis A virus is transmitted via fecal-oral route either by direct contact with a person who is infectious or by ingesting contaminated food or water. Although it is a self-limited disease, there is significant morbidity caused by infection in adults with hospitalization. Acute fulminant hepatitis can result in occasional mortality too. ${ }^{3}$

\section{Objective}

To determine HAV infection seroprevalence, with serum, which was assessed for anti HAV immunoglobulin $\mathrm{M}$ (IgM) detection and its changing statistics over a 5 year period.

\section{Materials and Methods}

A cross-sectional study was conducted in the Department of Microbiology, KIMS Hubli, over a period of five years from January 2012 to December 2016. Samples of blood obtained from clinically suspected cases of hepatitis infection were subjected to IgM detection by 'capture' ELISA. The KIT used was ImmunoVision USA, for anti HAV IgM Antibody detection and the test was carried out as per instructions of the manufacturer. To reduce the false positivity rate, retesting of the initially reactive samples was done.

The institutional scientific and ethical committee clearance was obtained.

\section{Results}

Of 173 cases enrolled in the study, 104 were children $(<12 \mathrm{yrs})$ and 69 were adults $(>12 \mathrm{yrs})$, and $52.6 \%$ (91) were females and $47.4 \%$ (82) were males. The number of samples tested in the years 2012, 2013, 2014, 2015 and 2016 were 16, 5, 48, 64 and 40 respectively. 
Chart I: Changing trend in hav seropositivity from 2012 -2016

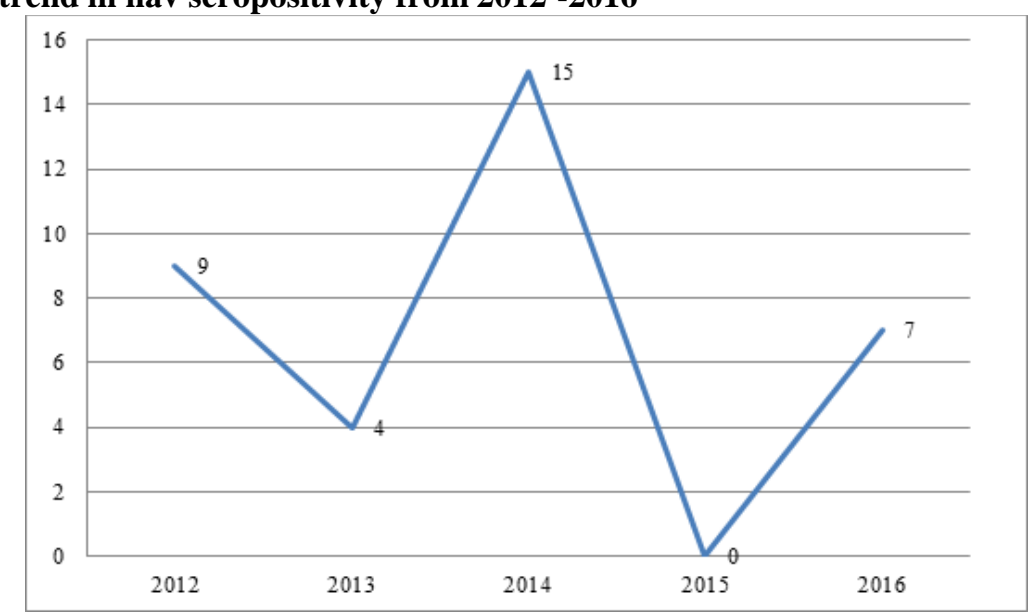

The total number of positive cases were $35(20.2 \%)$. The percentage positivity rate of anti HAV IgM was higher among the children tested 32(30.8\%) when compared to adults tested 3(4.3\%).

Seasonal distribution of HAV virus was analysed and was found that maximum number of seropositive cases occurred in the month of October followed by November, January and June in this region.

\section{Chart II: Seasonal distribution of HAV seropositivity}

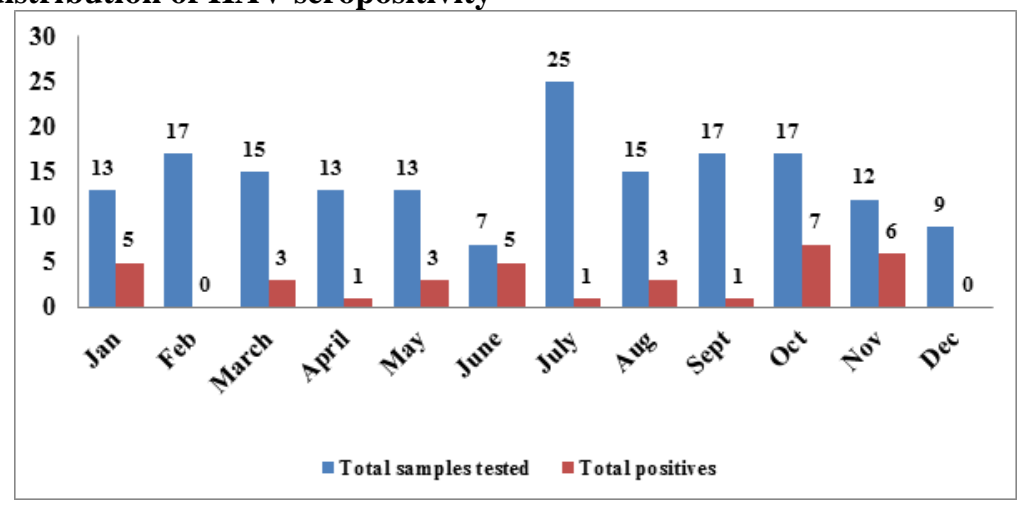

Table I: Districtwise break up: Prevalance of HAV

\begin{tabular}{|l|c|c|c|c|c|c|c|c|c|c|}
\hline & \multicolumn{2}{|c|}{2012} & \multicolumn{2}{c|}{2013} & \multicolumn{2}{c|}{2014} & \multicolumn{2}{c|}{2015} & \multicolumn{2}{c|}{2016} \\
\hline & Total & Positive & Total & Positive & Total & Positive & Total & Positive & Total & Positive \\
\hline Dharwad & 12 & 8 & 3 & 3 & 21 & 14 & 33 & - & 17 & 1 \\
\hline Haveri & 2 & 1 & 1 & - & 16 & - & 28 & - & 18 & 5 \\
\hline Gadag & 2 & - & - & - & 4 & - & 2 & - & 3 & 1 \\
\hline Koppal & - & - & - & - & 4 & 1 & - & - & 1 & - \\
\hline Belgaum & - & - & 1 & 1 & 2 & - & - & - & 1 & - \\
\hline Chitradurga & - & - & - & - & 1 & - & - & - & - & - \\
\hline Bijapur & - & - & - & - & - & - & 1 & - & - & - \\
\hline Total & 16 & 9 & 5 & 4 & 48 & 15 & 64 & 0 & 40 & 7 \\
\hline
\end{tabular}

\section{Discussion}

Hepatitis A virus (HAV) belongs to the Hepatovirus genus of the Picornaviridae family. It is a single-stranded RNA, non-enveloped virus. HAV replicates in liver cells and interferes with liver function, triggering an immune response which causes liver inflammation. Infection with any of the genotypes usually results in lifelong immunity against all strains of hepatitis A virus. ${ }^{3}$

Based on the endemicity of HAV infection, areas of the world can be identified as having high, intermediate and low endemicity. ${ }^{3}$ Worldwide, about 1.4 million cases of hepatitis A virus (HAV) infection occur every year. ${ }^{2,6}$ Being the world's second most populous country, India has shown a very rapid socio-economic development with a 
transition to moderate incidence of infection in the last few years. ${ }^{3}$ In our study the prevalence of HAV infection was $18.29 \%$.

Anti-HAV antibodies can be detected during acute illness when faecal HAV shedding is still occurring. The primary antibody response is mostly of the IgM class and may last for 6-12 months. The IgG class anti-HAV antibodies become the predominant type during the convalescent phase. ${ }^{8}$

HAV infection is common during childhood and is asymptomatic in this age group, which is also observed in our study with more number of positive cases in children. The risk of disease increases with age. In a study in India, $80 \%$ of 5-10 year-old children were seropositive for the disease. In the present study, 32 (30.8 \%) HAV cases was seen in children which was much higher when compared to adults 3(4.3\%).

A study carried out by Jain P et al. have reported HAV prevalence of $27.27 \%$ in children and $26.61 \%$ in adults which is similar to our study. ${ }^{1}$ An epidemiological shift in the age pattern of infection by HAV, has been reported by several studies from different parts of India as shown in table II. Since no such data is available from this part of the country, our study can contribute in formulating the recommendations and vaccine policy for HAV in this region.

Table II: Table showing prevalence of HAV among different parts of India ${ }^{1}$

\begin{tabular}{|l|l|c|c|}
\hline \multicolumn{1}{|c|}{$\begin{array}{c}\text { Year of } \\
\text { study }\end{array}$} & \multicolumn{1}{c|}{$\begin{array}{c}\text { Place of } \\
\text { study }\end{array}$} & $\begin{array}{c}\text { Total samples } \\
\text { studied }\end{array}$ & \% positive \\
\hline \multirow{2}{*}{2002} & \multirow{2}{*}{ New Delhi } & Adults-177 & $1.7 \%$ \\
\cline { 3 - 4 } & & Children-129 & $3.1 \%$ \\
\hline \multirow{2}{*}{2002 and 2007} & \multirow{2}{*}{ Chandigarh } & Children -172 & $64.5 \%$ \\
\cline { 3 - 4 } 2012 & \multirow{2}{*}{ Lucknow } & Adults-685 & $17.5 \%$ \\
\cline { 3 - 4 } $\begin{array}{l}\text { Present study } \\
(2012-2016)\end{array}$ & \multirow{2}{*}{ North Karnataka } & Adults-124 & $26.61 \%$ \\
\cline { 3 - 4 } & & Children-143 & $27.27 \%$ \\
\cline { 3 - 4 } & & Adults- 69 & $3(4.3 \%)$ \\
\hline
\end{tabular}

HAV which is transmitted through the fecal-oral route can be acquired by consuming contaminated water which can be either, by sewage-contamination or inadequate-treatment and processing of the water before consumption. This occurs more during the monsoon season during rains and floods, due to the mixing of contaminated soil in wells and rivers from which drinking water is obtained. ${ }^{6}$ Studies have found usually no seasonal peaks or a peak in monsoon and summer months of the year. ${ }^{1}$ This is similar to our study where the seropositivity peak is in the monsoon season of October and November followed by January and June.

Preventive measures with vaccination strategies: HAV infected persons can take days to months to return to their daily schedule like schooling or work and this can lead to losses in the society both economically and socially. ${ }^{7}$ Hence a vaccination schedule should be included if necessary to reduce this morbidity. People who should be routinely vaccinated with hepatitis A vaccine include all children between their first and second birthdays (12 through 23 months of age) and children and adolescents 2 through 18 years of age who live in states or communities where routine vaccination has been implemented because of high disease incidence.

Immunization against HAV is now routinely not recommended because its seroprevalence is high. Also the cost of antibody assay is lower compared to that of the vaccine for HAV. ${ }^{6}$ Routine vaccination is only recommended in persons who remain unaffected by the viral infection in early childhood.

Susceptible individuals $>5$ yrs of age can be offered HAV vaccination with pre-immunization screening. ${ }^{5}$ Anti-HAV antibody titre has declined to less than seventy percent in Indian adults owing to the improvement in sanitation and urbanisation ? According to ACIP recommendations, prevaccination testing for the presence of anti-HAV antibodies may be considered among populations expected to have high rates of previous HAV infection and natural immunity in order to reduce costs by not vaccinating persons already immune to HAV. An analyses based in Ireland which was cost-effective showed that vaccination is the choice of approach where HAV immunity is $45 \%$ or less, and when immunity is greater than $45 \%$, screening followed by vaccination should be performed. ${ }^{3}$

Passive immunization is safe for adults and children, pregnant or lactating women and immunosuppressed persons, but it only provides a limited duration of protection after a single Ig dose of 100 IU (6 months), leaving susceptibles available for infection following another exposure. Hence it must be readministered on a regular basis to ensure continuous protection. It is therefore expensive, unreliable to supply long-term protection, and considered obsolete, except for situations in which immediate protection is required. Moreover, Ig can interfere with immune response to vaccines which are live attenuated. ${ }^{3}$ 
In the poorly developed countries where sanitary and hygienic conditions are not well established, HAV infection infects most people in the early childhood and is endemic. Since the disease is mostly asymptomatic when it occurs in an early age, the disease is relatively less reported and outbreaks do not commonly occur. Surveillance systems need to be well-established in order to pick up the infections and outbreaks if any, earlier.

In countries like Asia, Africa, Central and South America the disease is highly endemic and more prevalent among young children because of the conditions like crowded houses, poor sanitation and improper water supplies which help in spread of the virus. $^{3}$

The Chinese State Drug Administration has developed and licensed a safe and immunogenic live attenuated HAV vaccine which is based on the $\mathrm{H} 2$ strain. Indian studies conducted recently with this vaccine have confirmed its safety profile and high immunogenicity. ${ }^{2}$

In May 2016, the Global Health Sector Strategy (GHSS) on viral hepatitis 2016-2021was endorsed by the World Health Assembly. This strategy calls for the elimination of viral hepatitis as a public health threat by 2030. ${ }^{9}$

\section{Conclusion}

Increase in the number of samples received during 2014 and 2015 and a zero positive rate in 2015 indicates a rise in the awareness about early detection of hepatitis A virus infection and its prevention. A steady increase in the number of HAV seropositive cases is seen in 2014 and a steep decline in 2015. Uniform and well structured protocols which monitor HAV cases and assess disease burden are necessary to capture and probe into the sudden rise in the seropositivity, as seen in the last four months of 2016 in our study.

\section{References}

1. Jain P, Prakash S, Gupta S, Singh KP, Shrivastava S, Singh DD, Singh J, Jain A. Prevalence of hepatitis A virus, hepatitis $B$ virus, hepatitis $C$ virus, hepatitis $D$ virus and hepatitis $\mathrm{E}$ virus as causes of acute viral hepatitis in North India: A hospital based study. Indian Journal of Medical Microbiology, 2013; 31(3): 261-5.

2. Franco E, Meleleo C, Serino L, Sorbara D, Zaratti L. Hepatitis A: Epidemiology and prevention in developing countries. World J Hepatol 2012;4(3):68-73.

3. The Global Prevalence of Hepatitis A Virus Infection and Susceptibility: A Systematic Review. Geneva 27, Switzerland World Health Organization 2010.

4. Kazemi SA, Mahram M, Koosha A, Amirmoghaddami HR .Seroprevalence of Hepatitis A in 7-10 Year-old Children. Iran J Ped .2007; 17 (1):47-51.

5. Mathur P, Arora NK. Epidemiological transition of hepatitis A in India: Issues for vaccination in developing countries. Indian J Med Res 2008;128:699-704.
6. Quarterly Newsletter from the National Centre for Disease Control (NCDC).2014;3(1):1-3.

7. Rakesh P S, Sherin D, Sankar H, Shaji M, Subhagan S, Salila S. Investigating a community-wide outbreak of hepatitis A in India. J Global Infect Dis 2014;6(2):59-64.

8. Joon A, Rao P, Shenoy S M, Baliga S. Prevalence of Hepatitis A virus (HAV) and Hepatitis E virus (HEV) in the patients presenting with acute viral hepatitis. Indian $\mathrm{J}$ Med Microbiol 2015;33(S1):102-5.

9. Global Hepatitis report, 2017. World Health Organisation. Available from http://www.who.int/hepatitis/publications/globalhepatitis-report2017/en.

How to cite this article: Shankar MK, Sharon VA. Seroprevalence of Hepatitis- A virus in North Karnataka and its changes over a 5 year period. Indian J Microbiol Res 2018;5(1):76-79. 